\title{
Differential regulation of spermatogenic process by Lkb1 isoforms in mouse testis
}

\author{
Feifei Kong ${ }^{1}$, Mei Wang ${ }^{1}$, Xiaojing Huang ${ }^{2}$, Qiuling Yue ${ }^{1}$, Xiang Wei', Xiaowei Dou ${ }^{1}$, Xiaoxu Peng ${ }^{1}$, Yuanyuan Jia ${ }^{1}$, Ke Zheng', \\ Tinghe $\mathrm{Wu}^{*, 3}$, Jun Yan ${ }^{*, 2,4}$ and Jing Li*,
}

Liver serine/threonine kinase B1 (LKB1) is a tumor suppressor associated with the pathogenesis of Peutz-Jeghers syndrome. Affected males are at increased risk of developing Sertoli cell tumors and display defective spermatogenesis. Male mice lacking the short isoform ( $L k b 1_{s}$ ) of $L k b 1$ were sterile and exhibited abnormal spermiogenesis. In addition to the short isoform, the long isoform of $L k b 1\left(L k b 1_{L}\right)$ is also expressed in testis; however, the requirement of the long isoform for fertility and the functional difference between the isoforms remain unknown. Herein, different from the spermiation failure reported in Lkb1 $s$ knockout mice, conditional deletion (cKO) of both isoforms of $L k b 1$ in germ cells resulted in male sterility stemming from defects in acrosome formation, as well as nuclear elongation and condensation during spermatid differentiation. Additionally, cKO mice showed a progressive germ cell loss that was never reported in mice with $L k b 1_{s}$ deletion. Further experiments revealed that the defect resulted from the failure of spermatogonial stem/progenitor cells (SPCs) maintenance. Although increased mTORC1 activity in postnatal cKO testes was consistent with a tendency toward germline stem cell differentiation, in vivo inhibition of the pathway by rapamycin treatment failed to rescue the phenotype. Concurrently, we detected a significant reduction of mitochondrial activity in Lkb1deficient SPCs. The results suggest that the regulation of LKB1 on SPCs' maintenance is associated with mitochondrial functions but not through the mTOR signaling pathway. In summary, our study supports different roles of $L k b 1$ isoforms in spermatogenesis with $L k b 1_{L}$ directing SPCs maintenance, and $L k b 1_{L}$ and $L k b 1_{S}$ coordinately regulating spermatid differentiation. Cell Death and Disease (2017) 8, e3121; doi:10.1038/cddis.2017.527; published online 12 October 2017

Liver kinase B1 (Lkb1), also known as Serine/Threonine protein kinase 11 (Stk11), encodes an evolutionarily conserved serine/threonine kinase required in many physiological processes. ${ }^{1}$ The well-known downstream substrates of LKB1 are AMP-activated protein kinase (AMPK), and 12 other AMPK-related kinases. Tremendous progress over the last few years revealed that LKB1 negatively regulates mammalian target of rapamycin complex 1 (mTORC1) activity through its substrate AMPK, and the loss of LKB1 leads to the aberrant activation of mTORC1 in a variety of tissues. ${ }^{2}$ In brief, the LKB1/AMPK/mTORC1 cassette constitutes a canonical signaling pathway that integrates information on the metabolic and nutrient status to regulate many biological processes including cell proliferation, cell survival and autophagy.

Many studies have shown the tissue-specific functions of $L k b 1$ in pancreas, skin, muscle and gastrointestinal tissues. ${ }^{3-5}$ In testis, the function of LKB1 was not clearly described until knockout of an alternate splice variant was reported to cause sterility in mice. ${ }^{6}$ The newly identified isoform was termed LKB1 short form $\left(\mathrm{LKB} 1_{\mathrm{S}}\right)$ as opposed to the previously reported long form $\left(\mathrm{LKB} 1_{\mathrm{L}}\right){ }^{6}$ The two proteins are identical except for the C-terminus, which is encoded by different exons, 9A versus 9B for $L K B 1_{L}$ and $L K B 1_{S}$, respectively and thus differ in length.
Although both isoforms are widely expressed in rodent and human tissues, $L k b 1_{S}$ is particularly abundant in haploid spermatids. ${ }^{7}$ Male mice that cannot generate $L k b 1$ sare sterile with abnormal release of mature spermatids from the seminiferous epithelium. ${ }^{7,8}$ Spermatogenesis is a unique physiological process, during which diploid spermatogonial stem/progenitor cells (SPCs) undergo a series of differentiated steps, followed by meiosis and spermatid differentiation, and culminate in the production of mature haploid sperm cells. Although $L k b 1_{S}$ is the dominant isoform in germ cells (round spermatids), ${ }^{8}$ it remains unknown if the $L k b 1_{L}$ isoform is expressed in germ cells and if the two isoforms function redundantly or indispensably during the process of spermatogenesis.

Herein, we report the differential expression of the two isoforms of $L k b 1$ in different spermatogenic cell types with $L k b 1_{S}$ mainly expressed in spermatids and $L k b 1_{L}$ in SPCs, respectively. After conditional deletion (cKO) of $L k b 1$ in male germ cells, mice were sterile as evidenced by severe defects on round spermatid differentiation and flagellum biogenesis. Meanwhile, these cKO mice also suffered a progressive loss of germ cells, resulting in a Sertoli-cell-only phenotype. Further experiments demonstrated the essential roles of Lkb1 in SPCs maintenance and spermatid differentiation.

\footnotetext{
${ }^{1}$ State Key Laboratory of Reproductive Medicine, Nanjing Medical University, Nanjing 210029, China; ${ }^{2}$ State Key Laboratory of Pharmaceutical Biotechnology and MOE Key Laboratory of Model Animals for Disease Study, Model Animal Research Center, Nanjing University, Nanjing 210008, China; ${ }^{3}$ Department of Biotechnology and Biomedicine, Yangtze Delta Region Institutes of Tsinghua University, Jiaxing 314006, China and ${ }^{4}$ Collaborative Innovation Center for Genetics and Development, Shanghai 200438, China *Corresponding author: T Wu, Department of Biotechnology and Biomedicine, Yangtze Delta Region Institutes of Tsinghua University, Room 1002, 705 Yatai Road, Jiaxing 314006, China. Tel/Fax: 86-573-82586633; E-mail: wuth@tsinghua-zj.edu.cn

or J Yan, State Key Laboratory of Pharmaceutical Biotechnology and MOE Key Laboratory of Model Animals for Disease Study, Model Animal Research Center of Nanjing University, 12 Xuefu Road, Nanjing, Jiangsu 210061, China. Tel/Fax: 86-25-58641535; E-mail: yanjun@nju.edu.cn

or J Li, State Key Laboratory of Reproductive Medicine, Nanjing Medical University, Room B101, Xuehai Bldg, 818 Tianyuandonglu, Nanjing, Jiangsu 210029, China. Tel/Fax: 86-10-86869503; E-mail: ljwth@ njmu.edu.cn

Received 01.4.17; revised 28.7.17; accepted 04.9.17; Edited by M Agostini
} 


\section{Results}

Distinct expression of $L k b 1_{L}$ and $L k b 1_{S}$ in different spermatogenic cell types. To delineate the roles of LKB1 in male germ cells during spermatogenesis, we first examined the expression of the two isoforms of $L k b 1$ in the different germ cell stages including spermatogonial stem cells (SSC), spermatocytes (SP), round spermatids (RS) and
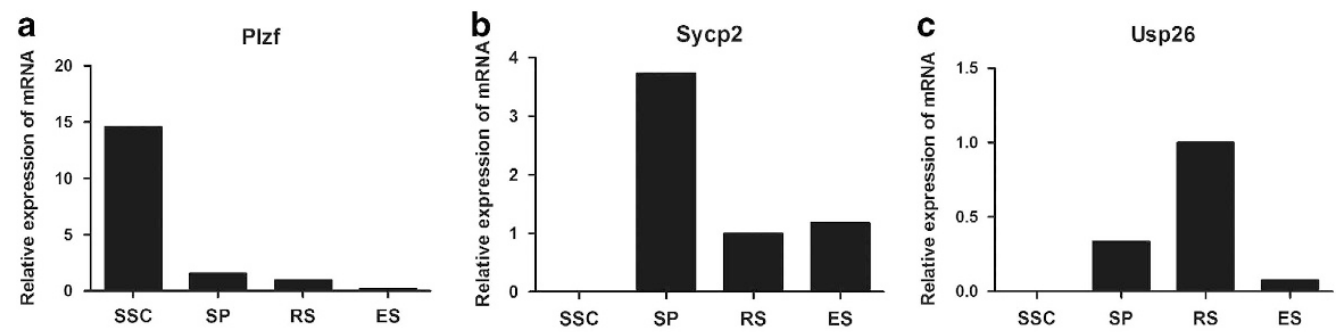

$\mathrm{d}_{\text {Expression of } L k b 1_{S} \text { and } L k b 1_{L} \text { in germ cells }}$
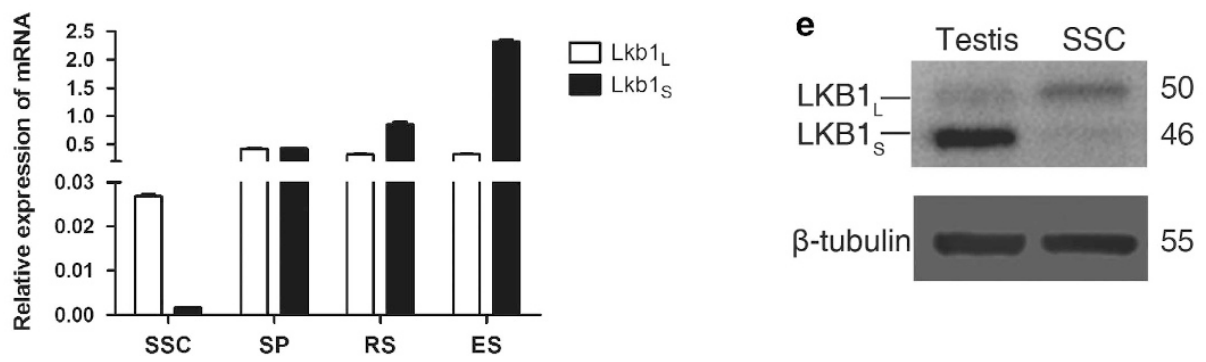

Figure 1 Expression of $L k b 1_{L}$ and $L k b 1_{S}$ in different spermatogenic cell types. Spermatogenic cells at different developmental stages (SP - spermatocytes, RS - round spermatids and ES - elongated spermatids) were sorted from pooled adult testes via STA-PUT velocity sedimentation. Mouse SSCs were enriched from P8 testes and cultured in vitro for at least five passages. All experiments were performed with at least three replicates. (a-c) The purity of these cells was confirmed by RT-PCR using markers: (a) Plzffor SSC, (b) Sycp2 for SP, (c) Ups26 for CS and ES. (d) RT-PCR for Lkb1 $1_{L}$ and $L k b 1$ stranscripts in each spermatogenic cell type. (e) Western blot analysis of Lkb1 $L$ and Lkb1 sin adult testis and SSCS

a

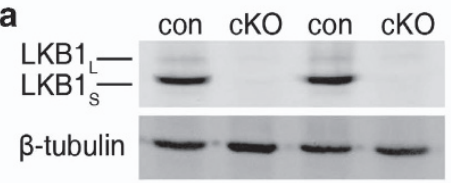

b

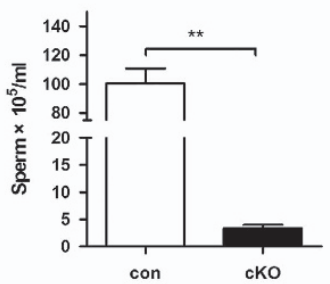

C

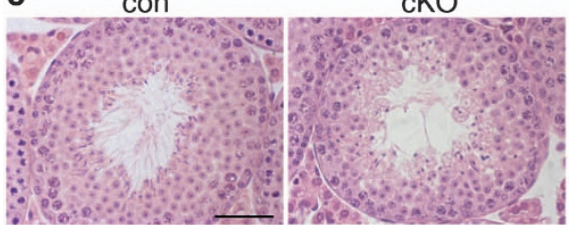

d

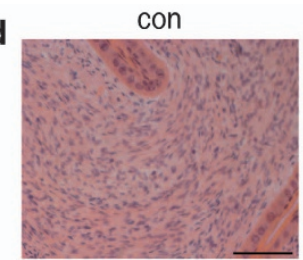

e

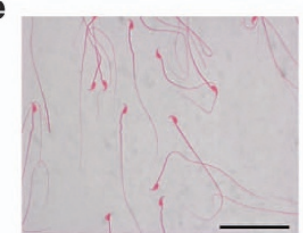

f

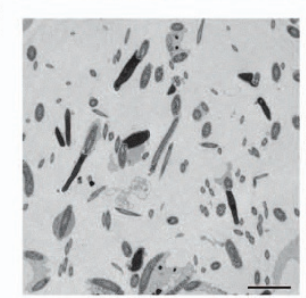

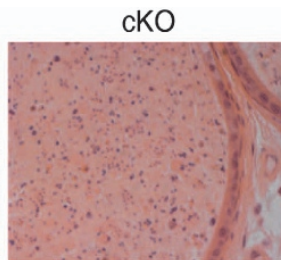
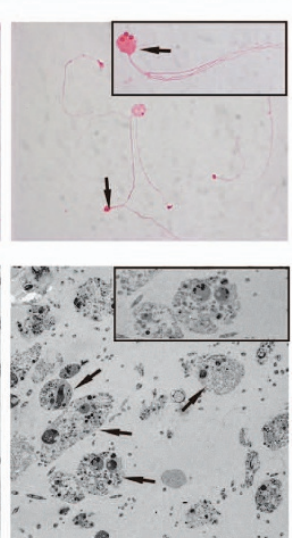

Figure 2 Effect of conditional deletion ( $\mathrm{cKO}$ ) of $L k b 1$ in germ cells on spermatogenesis and epididymal sperm morphology. Testes were collected from control (con) and cKO mice for western blot and H\&E staining at 5 weeks of age. Sperm were collected from cauda epididymides at 13 weeks of age for analysis. All experiments were replicated at least three times. (a) Significant decrease of Lkb1 proteins in Lkb1 cKO mice. (b) Sperm count from cauda epididymides. ${ }^{* \star} P<0.01$. (c) Representative tubules in 5-week-old control and cKO testes. Scale bar $=50 \mu \mathrm{m}$. (d) Histology of epididymal tubules and sperm analysis. Scale bar $=50 \mu \mathrm{m}$. (e) Spermatozoa morphology in control and cKO mice. Black arrows, abnormal multinucleated and multiflagellated sperm. Scale bar $=50 \mu \mathrm{m}$. (f) Transmission electron microscopy of sperm in the epididymis. Black arrows and inset, multinucleated sperm. Scale bar $=5 \mu \mathrm{m}$ 
elongated spermatids (ES). The purity of each isolated spermatogenic cell type was confirmed by enrichment assay on their corresponding marker gene expression, such as Plzf for SSCs, Sycp2 for SPC and Usp26 for RS and ES (Figure $1 \mathrm{a}-\mathrm{C}) .{ }^{9-11} \mathrm{Lkb1}_{\mathrm{S}}$ was predominantly expressed in differentiated germ cells (SP, RS and ES) and a marked increase was observed in RS and ES. $L k b 1_{L}$ was expressed in these cell types but maintained a stable expression level. Unlike $L k b 1_{S}$, $L k b 1_{L}$ was detected at a considerable level in SSCs, albeit its expression level was lower than that in other cell types (Figure 1d). Western blot analysis further demonstrated that
$L K B 1_{S}$ is the main isoform expressed in testis, while $L K B 1_{L}$ is the main isoform in SSCs (Figure 1e). The developmentally differential expression pattern of two $L k b 1$ isoforms points to their potentially discrepant regulatory functions in spermatogenesis.

Defects of spermiogenesis in $\mathbf{L k b 1} \mathbf{c K O}$ mice. To study the functions of $L k b 1$ in germ cells, we conditionally deleted $L k b 1$ in the male germ line by means of Vasa-Cre (Ddx4-Cre) and the flox'd allele $L k b 1^{\text {loxp }}{ }^{12}$ The result of western blot confirmed the mutation in cKO testis (Figure 2a). As
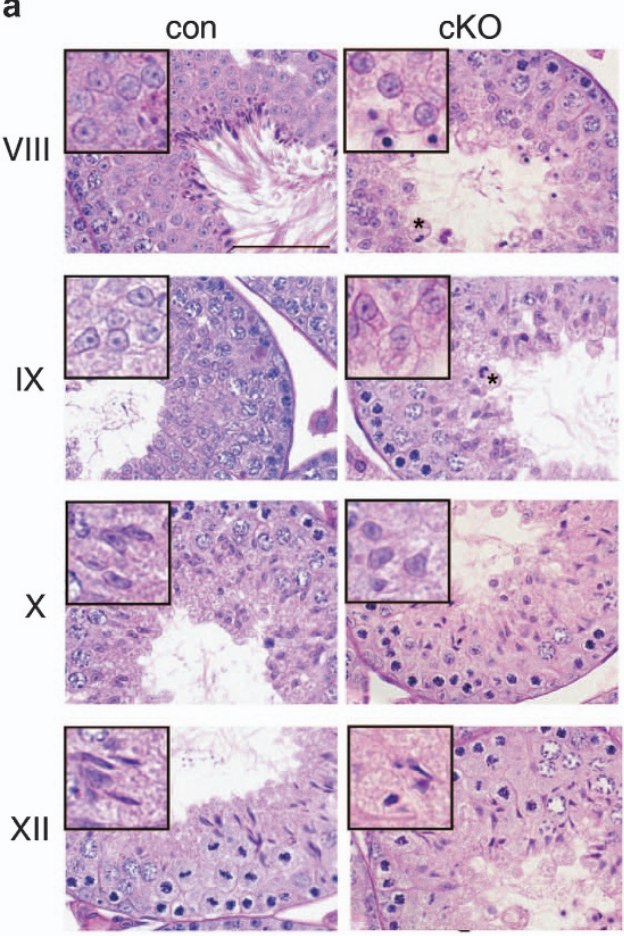

b

$\|-\|$

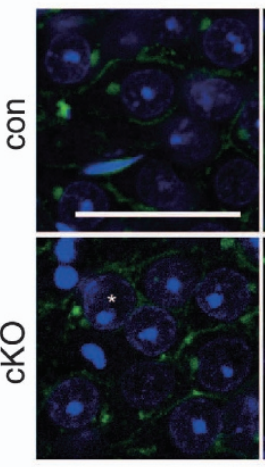

C

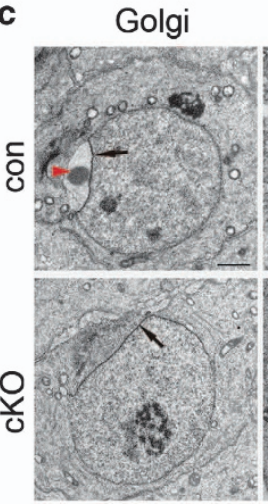

IV

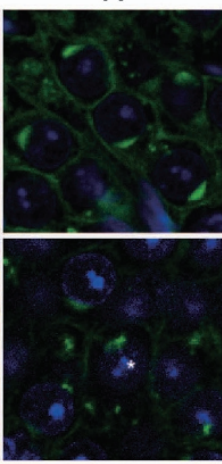

Cap

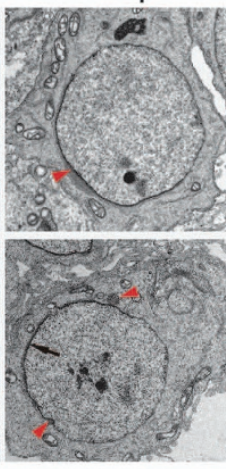

V

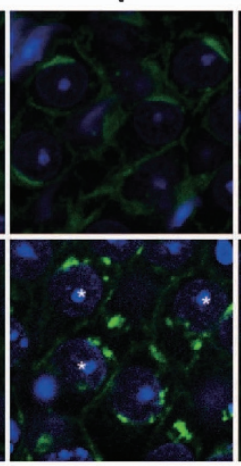

Acrosome

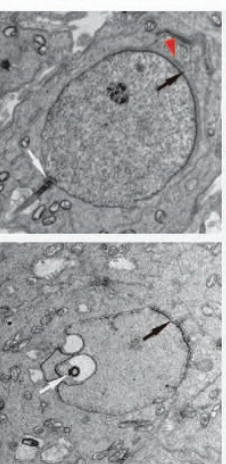

VIII

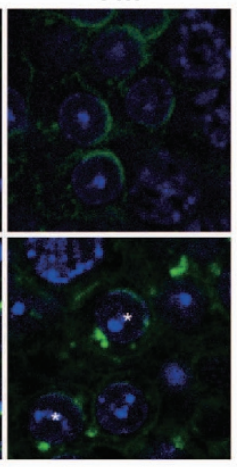

Maturation d

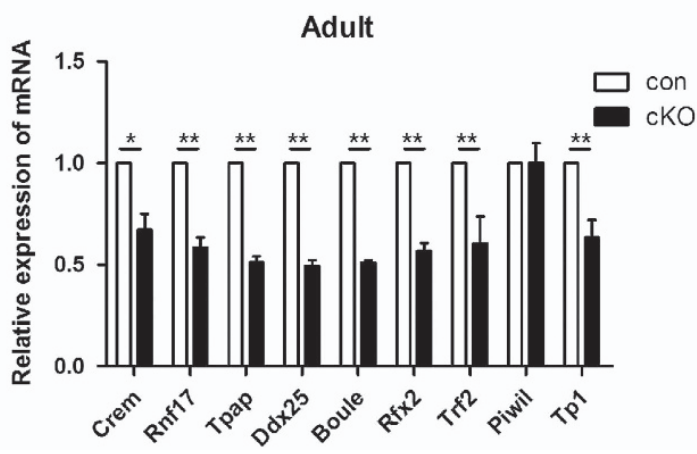

e

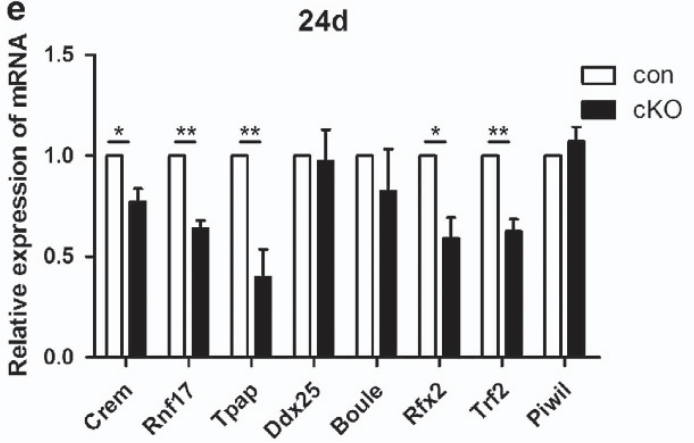

Figure 3 Abnormal acrosomal biogenesis in Lkb1 cKO mice. Testes from both control and cKO mice $(n=3)$ were collected at 6 weeks of age for tubule analysis. (a) Representative images of control and comparable cKO testis sections are shown at developmental stages I-VIII, IX, X and XII. Asterisks mark giant and round cells. Scale bars $=50 \mu \mathrm{m}$. (b) Higher magnification of acrosomes stained by fluorescently tagged peanut agglutinin at different stages of spermatogenesis. Scale bars $=25 \mu \mathrm{m}$. Asterisks, round spermatid with multiple pre-acrosomal vesicles. (c) Ultrastructural analysis of acrosome formation in control and $L k b 1 \mathrm{cKO}$ spermatids. Arrowheads, acrosomal granules or acrosomes. Black arrows, closer leaflets of nuclear envelope. White arrows, developing axonemes or centriole-like organelle. Black asterisks, spermatid nuclei. Scale $\mathrm{bar}=1 \mu \mathrm{m}$. (d and e) RT-PCR analysis for spermiogenesis-related key regulator genes in adult (d) and P24 (e) control and cKO mice. Data are presented as means \pm S.E.M. of at least three replicates. ${ }^{\star} P<0.05$ and ${ }^{* \star} P<0.01$, compared with control mice. The level of mRNA expression in control mice was given an arbitrary value of 1 
expected, $L k b 1 \mathrm{cKO}$ male mice were infertile. The average sperm count in cKO mice was $3.4 \times 10^{5}$ spermatozoa per epidydimis, which accounted for a $>96 \%$ reduction as compared with control group (Figure 2b). Moreover, the sperm heads were invariably round with most displaying multi-nucleation and/or multi-flagella (Figure 2e). Upon histological evaluation, in cKO mice the epididymal lumen was filled with sloughed germ cells or cell debris (Figure 2d). Transmission electron microscopy further demonstrated that this debris consisted of degraded multinucleated germ cells (Figure 2f). Testis sections from 5-week old control and cKO mice were used to analyze the first wave of spermatogenesis. In control mice, mature spermatozoa observed at the luminal interface. By contrast, multinucleated giant round cells were frequently observed towards the center of the tubule in cKO mice (Figure 2c). These results suggest that the dramatic reduction of spermatozoa in the epidydimis stemmed from a failure in the process of spermiogenesis.

Lack of acrosome formation in Lkb1 cKO mice. In mammals, spermiogenesis is characterized by a massive wave of transcriptional activity and can be accurately divided into continuous steps on the basis of nuclear elongation and acrosome morphology. ${ }^{13}$ To further assess potential defects in spermiogenesis stemming from the $L k b 1 \mathrm{cKO}$ phenotype, we first compared spermatid nuclear elongation between similarly staged seminiferous tubules from control and cKO mice at 6 weeks of age. At stages from I to VIII, round spermatids with a spherical, central nucleus were commonly observed in both control and cKO mice. However, in stages $\mathrm{IX}$ and $\mathrm{X}$, progressive elongation and condensation of spermatid nucleidid did not occur in cKO tubules (Figure 3a). We next used fluorescently tagged peanut agglutinin to label and follow acrosome development. In rodents, acrosome development begins early in the spermiogenic process and can be divided into four phases (Golgi, Cap, Acrosome and Maturation) comprising the transformation from round spermatids to mature spermatozoa. ${ }^{14}$ The Golgi and Cap phases, which encompass the formation of a large acrosome granule (Golgi) and its growth and flattening over the nucleus (Cap phase), were observed in stages IIVIII round spermatids from control mice (Figure 3b, upper panel). However, only occasionally, two pre-acrosomal vesicles could be observed associated with the nucleus in stages II-III round spermatids from cKO mice (Figure 3b, lower panel). Moreover, Cap flattening was seldom observed in stages IV-VIII cKO tubules and, instead, pre-acrosomal granules failed to fuse and appeared scattered over the spermatid nucleus (Figure $3 b$, lower panel). TEM analysis revealed the typical acrosomal granule and cap structure over round spermatids at Golgi phases in control mice (Figure 3c). Then, cap flattening continued through acrosome-acroplaxome complex formation and culminating in acrosome development. Although the closer leaflets of nuclear envelope could be identified at the beginning of the acrosome formation in cKO mice (Figure 3c, black arrows), it lacked a typical large acrosomal granule; furthermore, it failed to form the cap structure and instead displayed small granules scattered and attached over the nuclear membrane in Cap phase (Figure 3c, red arrowheads, cKO versus control).
Additionally, localization of the centriole distally to begin formation of the flagellum as observed by Acrosome phase in control tubules was not observed in spermatids from cKO spermatids (Figure 3c, white arrow). Taken together, the failure of acrosome and flagellum genesis observed in round spermatids impaired nuclear elongation and remodeling and ultimately lead to abnormal spermatozoal maturation in cKO mice.

At the round spermatid stage, a large number of testisspecific genes are expressed under the control of a limited number of key regulator genes, including Crem, Trf2, Rnf17, Piwil1, Boule, Tpap, Ddx25 and Rfx2. ${ }^{15-24}$ To investigate the potential role of $L k b 1$ in spermiogenesis regulation, we compared the mRNA expression of these key regulator genes in adult testes of control and cKO mice. Notably, in cKO testes there was a global significant decrease in the expression of all genes examined except Piwil1 (Figure 3d). Then, to rule out whether the decreased gene expression levels stemmed directly from faulty transcriptional regulation by Lkb1 rather than the altered ratio of cell types in adult testis, we repeated these experiments in testes from 24-day-old mice, tubules from both control and cKO mice presented a similar histomorphology (Supplementary Figures S1a,b). In agreement, at this age, cKO mice also showed a significant downregulation of most genes examined (Figure 3e). Altogether, these results suggest that loss of Lkb1 may disrupt spermatid gene transcription.

Progressive loss of germ cells in cKO mice. While a link between $L k b 1_{S} \mathrm{KO}$ and male sterility resulting from spermiogenetic defects was previously reported, no phenotypes were reported on the other stages of spermatogenesis. ${ }^{8}$ In this study, we recorded a gradual decrease in testis weight with advancing age (Figures $4 \mathrm{a}$ and $\mathrm{b}$ ). Histology analysis also showed a progressive loss of germ cells in seminiferous tubules that finally resulted in Sertoli-only tubules (Figure 4c). The loss of spermatogenic cells began after 5 weeks of age and, by 13 weeks, tubules undergoing various degrees of germ cell loss were widespread in CKO testis' sections (Figure 4c; Supplementary Figures S1c-g). By 40 weeks, cKO testes became completely atrophic and nearly $90 \%$ were Sertoli-only tubules (Figure 4d). These results are consistent with a normal onset of spermatogenesis in juvenile cKO mice followed by an age-dependent progressive deletion of spermatogenic cells from the seminiferous tubules.

Depletion of SPCs in $\mathbf{L k b 1}$ cKO mice. To investigate the underlying cause for the scarcity of spermatogenic cells observed in cKO seminiferous tubules, we used the TUNEL assay to assess apoptosis in 5- and 13-week-old control and cKO testes. Although apoptotic cell counts increased in 13week cKO testis, numbers were still low ( $\sim 1.2$ apoptotic cells per tubule) and there was no preference for any specific cell type (Figure 4e). These results suggested that the testicular atrophy observed in cKO mice was not caused by induction of apoptosis. We then used stage-specific spermatogenic cells markers to assess at which developmental stage germ cell loss was happening. These markers included: PCNA, a proliferation marker confined to the nuclei of spermatogonia and early spermatocytes; ${ }^{25} \mathrm{yH} 2 \mathrm{AX}$, in spermatocytes in meiotic prophase $1 ;{ }^{26}$ and PIzf, a SPC marker. ${ }^{27}$ In control 


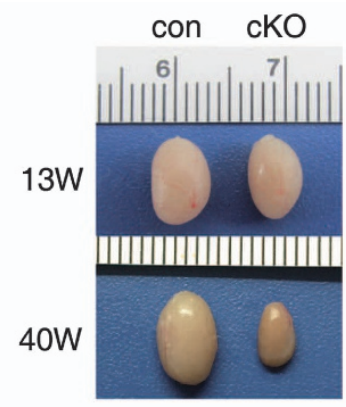

b

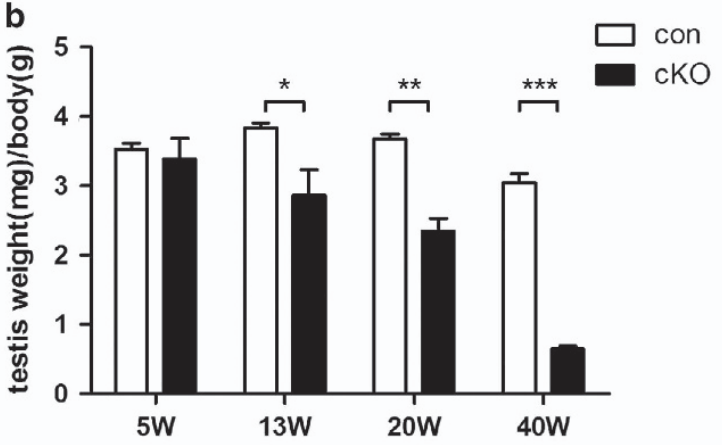

C $5 \mathrm{~W}$
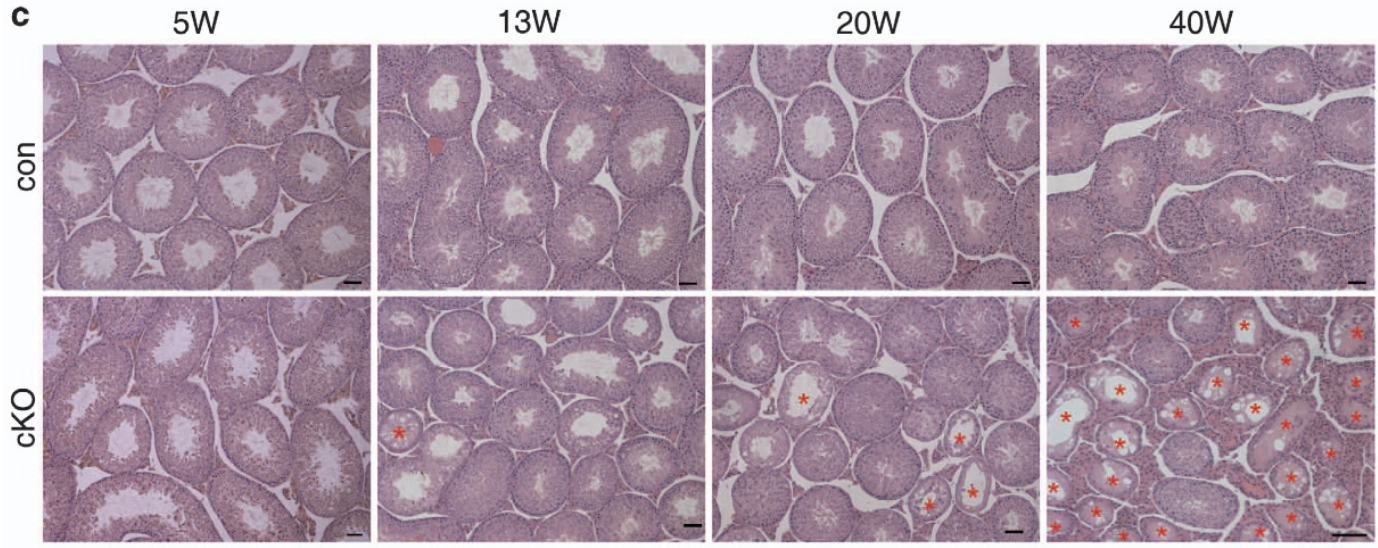

e
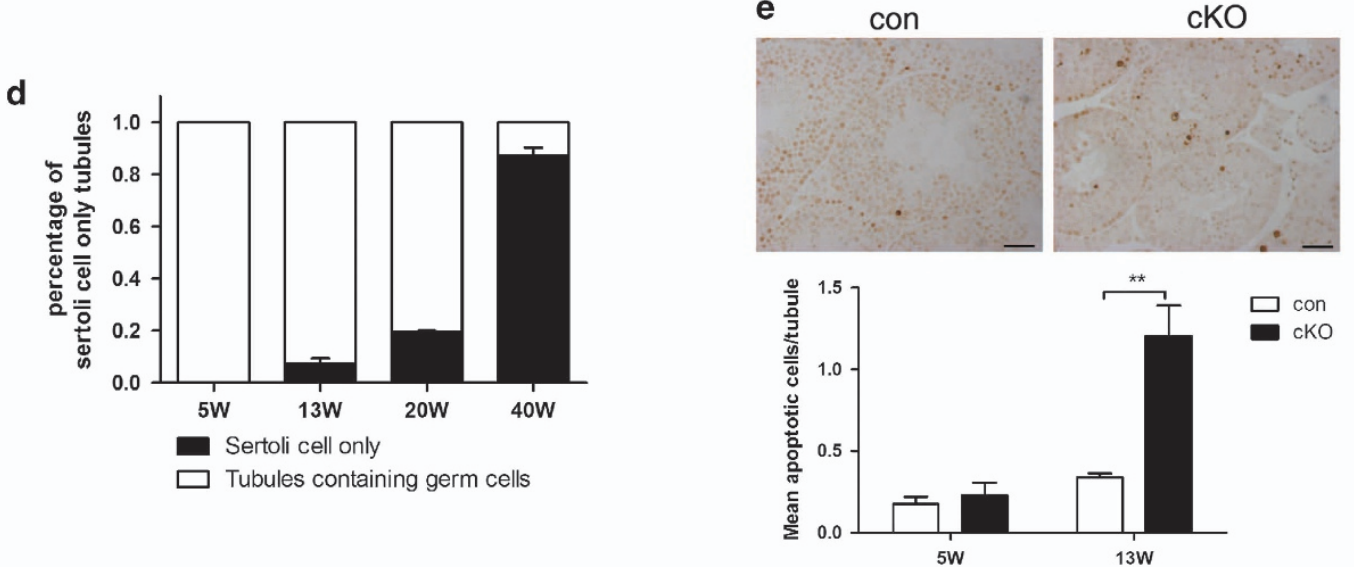

Figure 4 Gradual germ cell loss in Lkb1 cKO mice. Testes were collected from control and cKO mice $(n=3-5)$ at 5, 13, 20 and 40 weeks of age. (a) Testis gross appearance at 13 and 40 weeks of ages in both control and cKO mice. (b) Testis weight per body weight. (c) Histology of the seminiferous tubules. Scale bars $=50 \mu \mathrm{m}$. Red asterisks, Sertoli only tubules. (d) Percentage of Sertoli only tubules in each section. (e) Upper panel, TUNEL staining of seminiferous tubules in $13 W$ control and cKO mice. Lower panel, average number of apoptotic cells per tubule in 5- and 13-week-old testes by TUNEL staining. All data presented as mean \pm S.E.M. ${ }^{*} P<0.05 ;{ }^{* *} P<0.01$

testis, PCNA (Figures 5a and b, upper panel) and $\gamma \mathrm{H} 2 \mathrm{AX}$ (Figures $5 \mathrm{a}$ and $\mathrm{b}$, middle panel) were evenly and continuously distributed around the seminiferous tubules. Intriguingly, PCNA and $\gamma \mathrm{H} 2 \mathrm{AX}$ staining was comparable to that of controls in 5-week-old cKO mice (Figure 5a), but both of them decreased significantly by 13 weeks in cKO testes (Figure 5b). Strikingly, in opposition to the observations with PCNA and $\gamma \mathrm{H} 2 \mathrm{AX}$ labeling, the number of Plzf-positive cells was reduced as early as 5 weeks in cKO mice (Figures 5a and b). These results suggest that progressive depletion of SPCs is at the origin of germ cell loss in cKO mice.
The indispensable role of $L k b 1$ in SPC self-renewal and maintenance. A major advance in the study of male germline biology was the development of a culture system allowing long-term maintenance and expansion of mouse SSCs by in vitro culture. ${ }^{28}$ To investigate the effects of $L k b 1$ deletion on SSC survival and maintenance, we enriched SPCs using Thy-1 microbeads according to previous reports. ${ }^{29}$ Similar numbers of cells were separated and seeded onto STO feeder cells for culture. To our surprise, the $L k b 1 \mathrm{cKO}$ germ cells failed to form typical SSC colonies in culture (Figure 6b). After two passages, the $L k b 1 \mathrm{cKO}$ germ cells underwent complete depletion (Figure 6c). Freshly enriched SPCs from 
a
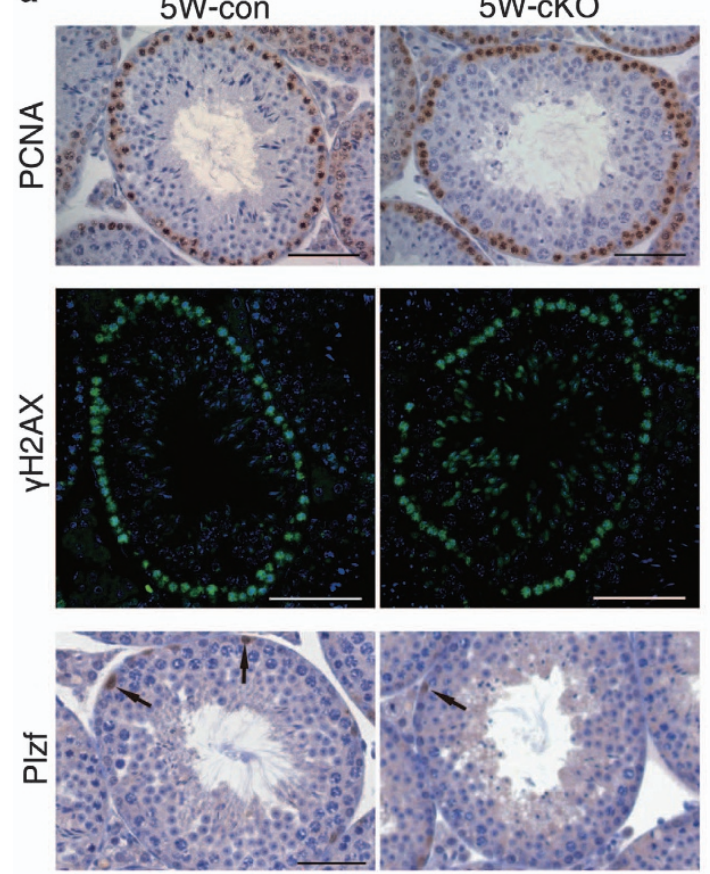

b
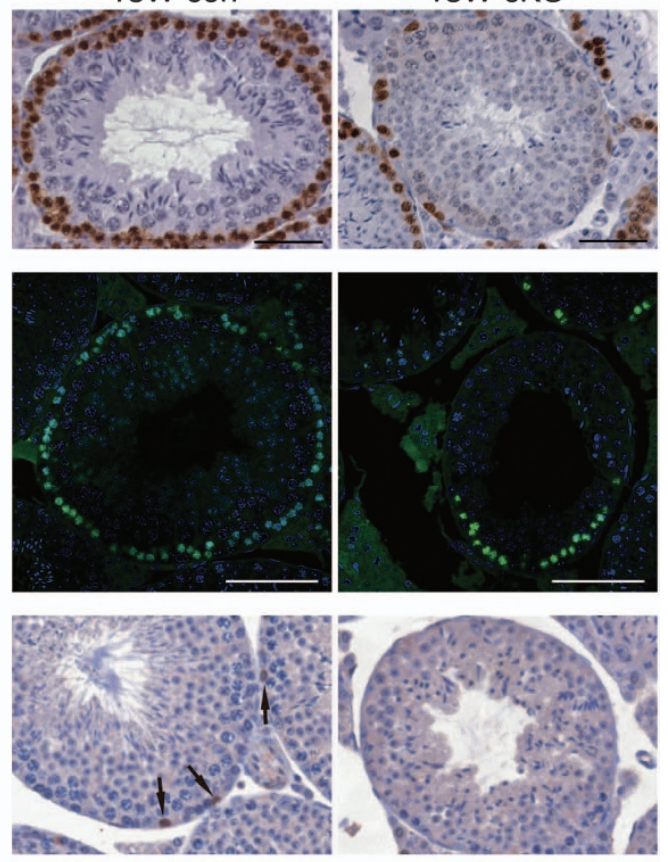

C

PIzf

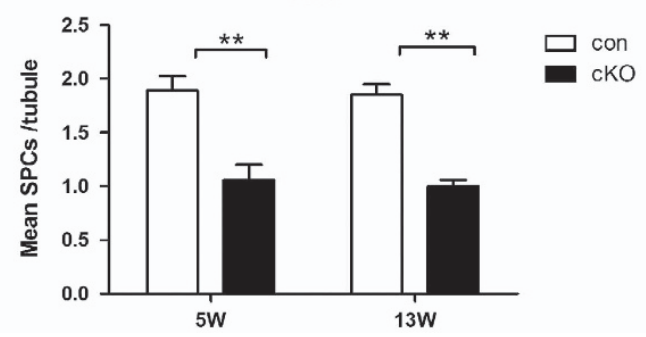

Figure 5 Depletion of SPCs in Lkb1 cKO mice. Seminiferous tubules from 5- (a) and 13- (b) week-old control and Lkb1 cKO mice $(n=3)$ were used for immunostaining using specific antibodies against PCNA, $\gamma \mathrm{H} 2 \mathrm{AX}$ and Plzf. Scale bars $=50 \mu \mathrm{m}$. Arrows, representative Plzf-positive cells in tubules. (c) Quantification of Plzf-positive germ cells in each tubule. Data are presented as mean \pm S.E.M. ${ }^{* \star} P<0.01$

control and cKO testis were then used to evaluate the expression of SSC self-renewal and differentiation-related genes by RT-PCR. As shown in Figure $6 \mathrm{~d}$, key regulators of SSC self-renewal including Oct4, Bcl6b, Nanos3, Id4, and Gfra 1 displayed decreased expression in $L k b 1 \mathrm{cKO}$ germ cells. ${ }^{30-32}$ Conversely, the expression of the SSC differentiation markers, Stra8 and c-kit was significantly upregulated in this population. ${ }^{33,34}$

The depletion of SPCs in cKO mice is independent of the mTOR signaling pathway but associated with mitochondria dysfunction. It has been reported in a variety of tissues that the inhibition of LKB1 signaling induced the aberrant activation of the mTOR signaling pathway. ${ }^{35-37}$ As a central signaling pathway in stem cell homeostasis, the aberrant activation of mTORC1 was recently shown to promote SSC differentiation in both mouse and Drosophila. ${ }^{35,38,39}$ Since RT-PCR revealed an increased expression of differentiation markers Stra8 and c-kit in freshly isolated SSCs from cKO mice, we assessed whether the mTOR signaling pathway was functioning downstream of LKB1 in regulating SSCs maintenance and differentiation in our model. Testes were collected at different age and the highest mTORC1 activity was detected at P8 (Figure 7a). We then used P8 testes to compare mTORC1 signaling between control and cKO mice. As shown in Figure $7 b, L k b 1$-deficient germ cells induced a significant increase in phosphorylated S6K1 and rpS6, but no effect on p-Akt, a marker of the PI3K signaling pathway. Additionally, Lin28 and Plzf showed similar expression in both control and cKO P8 testes at mRNA and protein levels (Figures $6 \mathrm{~d}$ and $7 \mathrm{~b}$ ). To investigate the origin of the aberrant activation of the mTOR signaling pathway, we then checked the localization of p-rpS6 on sections of control P8 testis using VASA as a germ cell marker, GATA4 as a Sertoli cell marker and Lin28a, as a SPC marker. From the localization of VASA, p-rpS6 and GATA4, it was confirmed that the activation of $\mathrm{mTORC} 1$ was restricted to germ cells and not all VASA-positive germ cells are p-rpS6 positive (Figure 7c). Then we used Lin28a to label SPCs in the tubules and found p-rpS6 and Lin28a seldom co-localized in the same germ cell when serial sections were used for staining. Moreover, even when they were expressed in the same germ cell, the signal 
a

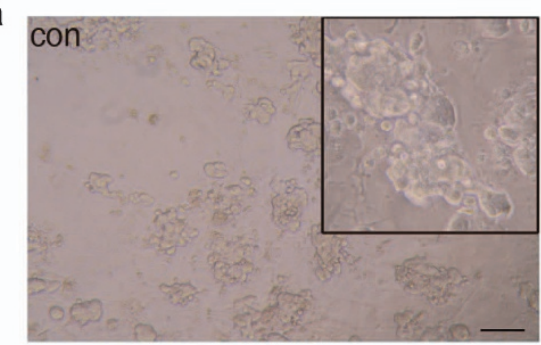

b

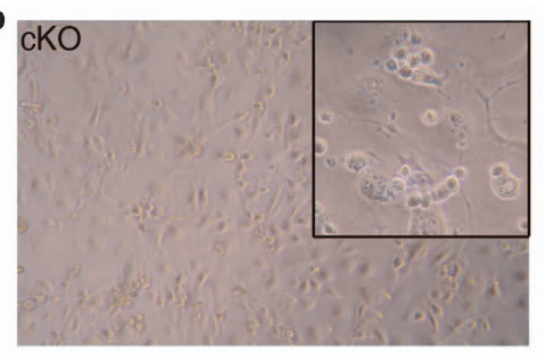

C

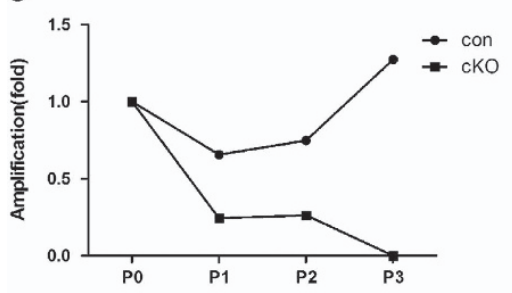

d

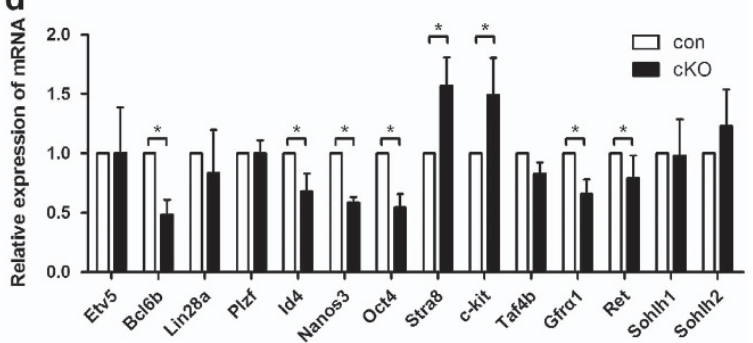

Figure 6 Requirement for Lkb1 in SPC maintenance. Testes from P8 control and cKO mice ( $n=2-4)$ were used for SPCs enrichment and culture. (a,b) Microscopic morphology of presumptive SSCs derived from P8 control (a) and $L k b 1 \mathrm{cKO}$ (b) mice, following in vitro culture at passage 2 . Insets, enlarged view of cells in culture. The culture was repeated for two times. Scale bar $=200 \mu \mathrm{m}$. (c) Amplification curve of control and $L k b 1 \mathrm{cKO}$ SPCs cultured in vitro. $y$ axis represents relative increase in the number of SPCs after subcloning (fold change of initially plated cell numbers in culture). (d) Comparative expression of spermatogonial self-renewal and differentiation-related genes in freshly isolated SPCs from control and cKO littermates $(n=3)$. The data were presented as mean \pm S.E.M. of at least three replicates. The level of mRNA expression in control mice was given an arbitrary value of $1 .{ }^{*} P<0.05 ;{ }^{*} P<0.01$

for both p-rpS6 and Lin28a was always lower than that of when expressed separately (Figure 7d, arrows). Because Lin28a expressed in both undifferentiated and differentiating spermatogonia, ${ }^{40}$ we then used PIzf to label undifferentiated germ cells and PIzf- and p-rpS6-positive cells were counted (Figure 7e). While there was only a little decrease of Plzfpositive germ cells in P8 cKO testes, p-rpS6-positive cells increased significantly in cKO testes with nearly twice as many as those in controls (Figure $7 f$ ). These results suggest that the abnormal higher activity of the mTOR signaling pathway may be related to the acceleration of spermatogonial differentiation in cKO testis.

Next, we assess whether rapamycin (the mTORC1 inhibitor) could reverse the loss of SSCs in cKO mice. We use testes just after injection to test Rapamycin effect and collect testes at 5 weeks of age for analysis. As expected, rapamycin treatment caused a significant decrease of testis per body weight in both control and cKO mice compared to that in vehicle-control mice (Figures $8 a$ and b). The level of p-rpS6 was dramatically reduced after injection and recovered to normal at 5 weeks of age (Figures $8 \mathrm{c}$ and $\mathrm{d}$ ). In control mice of the rapamycintreated group, the seminiferous tubules displayed a reduced diameter and a blockade of germ cell development at stages earlier than spermiogenesis (Figure $8 \mathrm{e}$, control+Rapa). Moreover, the number of Plzf-positive germ cells increased $\sim 1.4$ fold when compared with control vehicle-treated control testes (Figure 8f). However, rapamycin treatment in cKO mice did not have a rescue effect on SPCs accumulation in cKO mice (Figure $8 \mathrm{e}, \mathrm{cKO}+\mathrm{Rapa}$ ). In fact, the number of Plzf-positive cells was slightly below that of vehicle-treated cKO testes (Figure 8f). We infer from these results that although the deletion of $L k b 1$ in germ cells will yield an increase in the number of differentiating spermatogonia via upregulation of
mTORC1 activity, the regulation of Lkb1 on SSC self-renewal or maintenance is mTORC1-independent.

Since mitochondria dysfunction is associated with the failure of stem cell maintenance in Lkb1-deficient hematopoietic stem cells (HSCs), ${ }^{41}$ we next test the mitochondrial membrane potential $(\Delta \Psi \mathrm{m})$, a sensitive and reliable indicator of mitochondrial activity, in Lkb1-deficient SPCs by JC-1 staining. ${ }^{42}$ After a ratiometric analysis of $\mathrm{JC}-1$ staining, a significant reduction in $\Delta \Psi \mathrm{m}$ was observed in SPCs of $L k b 1$ cKO mice (Supplementary Figures S2a,b). Thus, instead of mTOR signaling pathway, the regulation of LKB1 on mitochondrial function may be essential in SSC maintenance and survival.

\section{Discussion}

Herein we showed that $L k b 1_{L}$ and $L k b 1_{S}$ functioned coordinately in regulating spermiogenesis, while $L k b 1_{L}$ also served as the key regulator for SSC maintenance. Previous studies showed that $L k b 1_{S} \mathrm{KO}$ male mice were infertile with defects in the release of mature spermatids. ${ }^{8}$ Moreover, $L k b 1_{S}$-deficient spermatozoa were immotile and presented head and tail morphological abnormalities. ${ }^{7}$ In our study, deletion of both $L k b 1$ isoforms from germ cells also resulted in sterility but more severe defects in spermiogenesis. Firstly, in addition to the coiled tails or round heads observed in spermatozoa from Lkb1s KO mice, most abnormal spermatozoa found within the epididymis of $L k b 1 \mathrm{cKO}$ mice were multinuclear and multiflagellar, something seldom seen in $L k b 1_{S} \mathrm{KO}$ mice. Secondly, the most striking difference between $L k b 1_{S} \mathrm{KO}$ and $L k b 1 \mathrm{cKO}$ testes was that the latter lacked elongated and condensing spermatids in their seminiferous tubules at stages VIII-XII. Further experiments showed that the severe defects on 
a

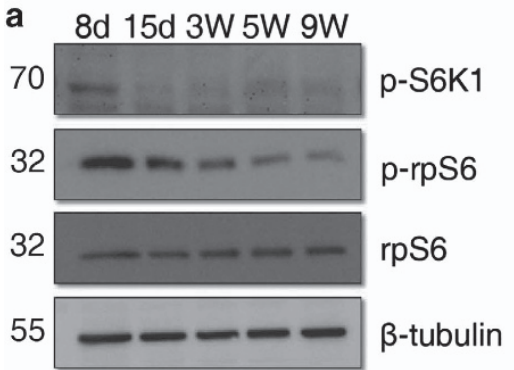

C
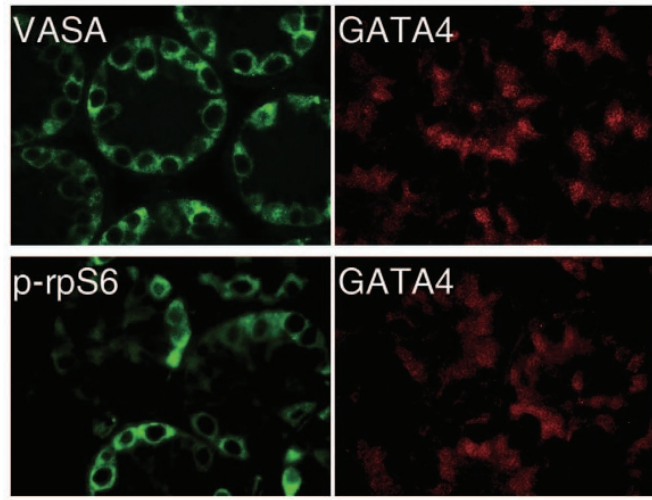

b

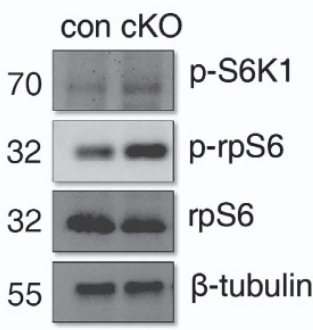

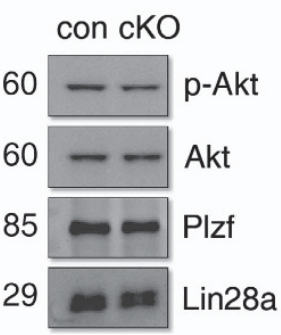

d
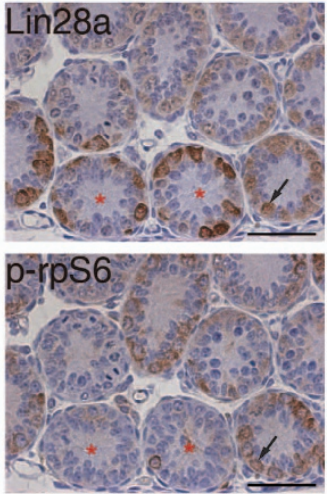

PIzf e

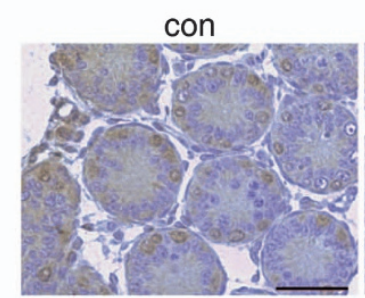

Plzf

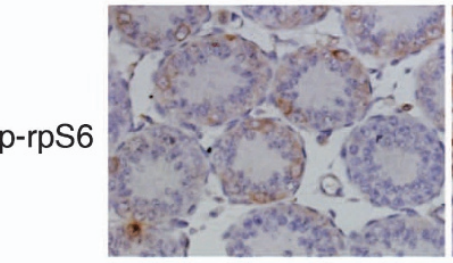

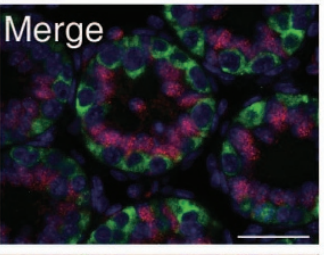

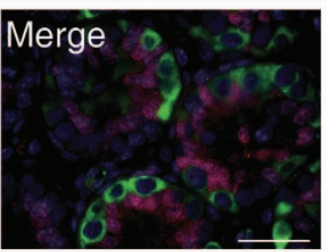

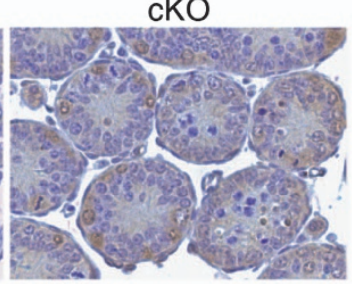

f
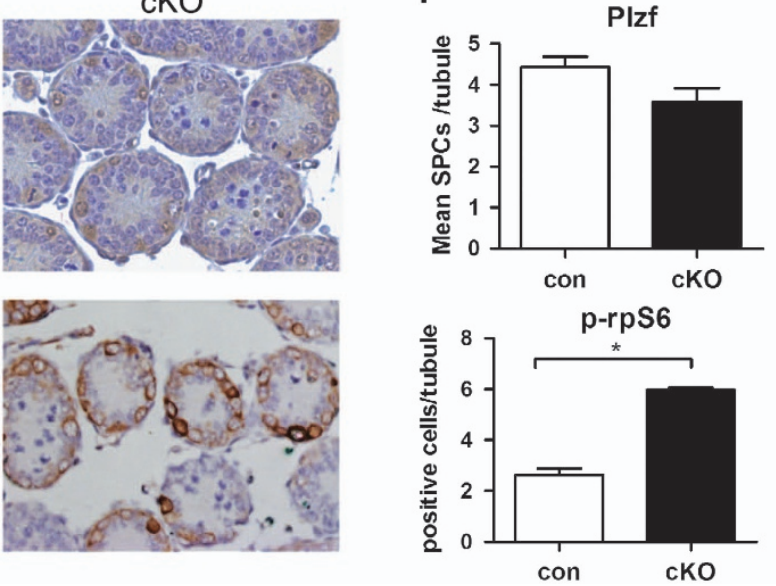

Figure 7 Increased mTORC1 activity in germ cells from Lkb1 newborn cKO testis. (a) Western blot of testis proteins at different postnatal ages using specific antibodies against p-S6K1 (T389), p-rpS6 (S235/6), rpS6 and $\beta$-tubulin. rpS6, and $\beta$-tubulin were used as internal controls. (b) Expression of PI3K-, mTOR- and SPC-related markers by western blot in P8 testes from control and Lkb1 cKO mice. (c) Immunohistochemistry for VASA, GATA4, p-rpS6 in P8 control testis. (d) Immunohistochemistry for Lin28a and p-rpS6 in P8 control testis. Serial sections were used in order to compare cellular localizations of these markers in the same tubule. Asterisks, different distribution of Lin28a and p-rpS6 in the same tubule resulting in strong positive for Lin28a and weak staining for p-rpS6. Arrows, cells expressing both Lin28a and p-rpS6. (e) Immunohistochemistry for Plzf and p-rpS6 in control and cKO mice. (f) Mean number of PIzf- or p-rpS6-positive cells in each tubule (positive cells/total tubules). The data were shown as mean \pm S.E.M. of at least three replicates. ${ }^{*} P<0.05$. Scale bars $=50 \mu \mathrm{m}$

acrosome formation happened as early as the beginning of the Golgi phase, which likely precluded the establishment of nuclear polarity and ultimately resulted in the failure on nucleus elongation and flagellar formation. ${ }^{13,43}$ There is growing evidence that LKB1 and AMPK play pivotal roles in the establishment of cell polarity in epithelial cells, ${ }^{4-47}$ intestinal paneth and goblet cells, ${ }^{4}$ and pancreatic $\beta$ cells. ${ }^{48,49}$ Recent studies show that a cytoplasmic linker protein of $170 \mathrm{kDa}$, CLIP-170, functions downstream of AMPK to affect cell polarity by shifting its binding sites to the more distal ends of microtubules. ${ }^{50}$ In mice, CLIP-170 has been identified to associate with the sperm manchette, and CLIP-170 knockout mice were subfertile and produced sperm with abnormal heads. ${ }^{51}$ Therefore, it is feasible that the same regulatory mechanism functions for LKB1-mediated nuclear polarization during spermatid differentiation. Despite tissuespecific differences, both $L k b 1_{L}$ and $L k b 1_{S}$ can activate AMPK and AMPK-related kinases in vitro. ${ }^{7}$ However, given the 
a

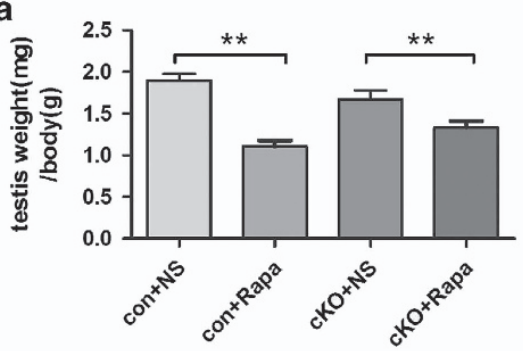

C
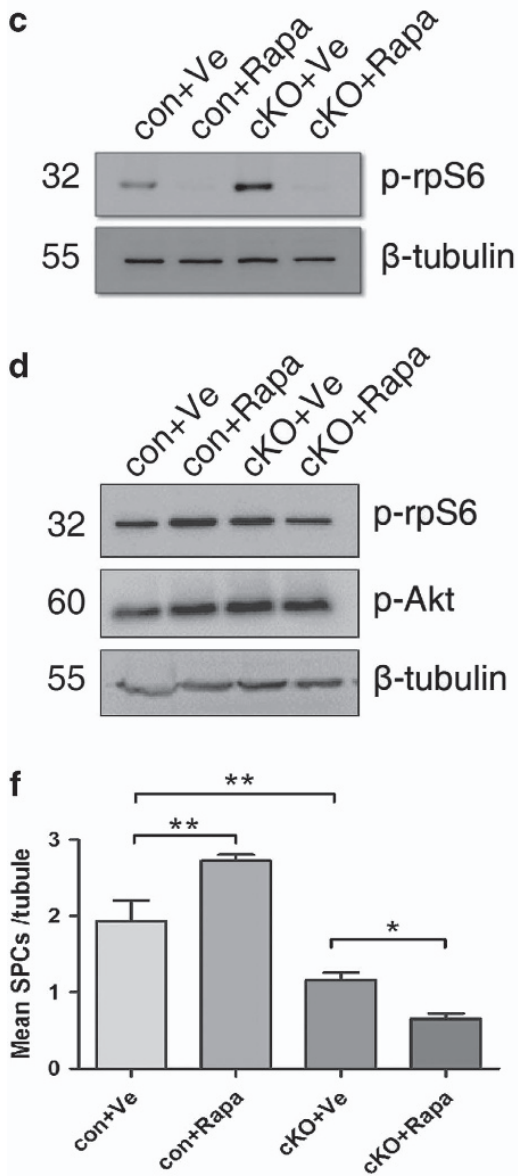

b

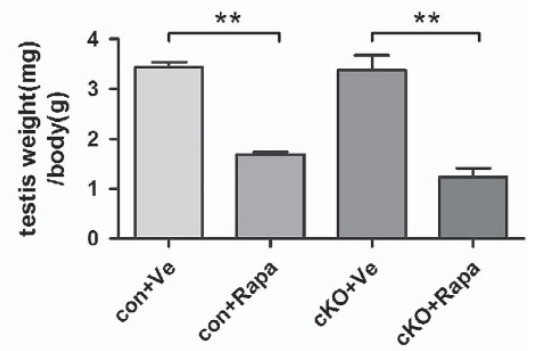

e
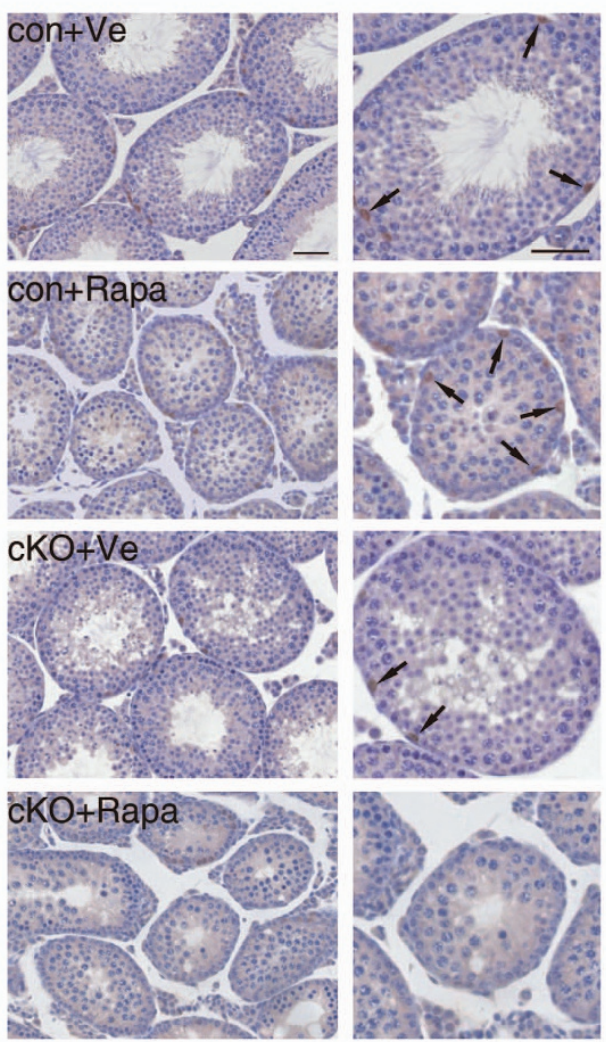

Figure 8 Rapamycin treatment failed to rescue the depletion of SPCs in the tubules of $L k b 1 \mathrm{cKO}$ mice. Rapamycin was given to $\mathrm{P} 10 \mathrm{control}$ and $\mathrm{cKO}$ mice $(n=5 \mathrm{in}$ each group) for 1 week, and testes were evaluated at 5 weeks of age. con+Ve, control mice injected with vehicle control saline; con+Rapa, control mice injected with rapamycin; cKO $+V e, c K O$ mice injected with vehicle control; cKO+Rapa, cKO mice injected with rapamycin. (a) Testis weight per body weight just after injection. (b) Testis weight per body weight at 5 weeks of age. (c) Western blot analysis of p-rpS6 level just after injection. (d) Western blot analysis of p-rpS6 and p-Akt level at 5 weeks. (e) Seminiferous tubules immunostained for Plzf. Scale bar $=50 \mu \mathrm{m}$. Images on the right column are higher magnifications of the relative tubules in the left. Arrows, representative Plzf-positive SPCs in the tubules. (f) Average number of Plzf-positive cells per tubule in each of the four groups. Data presented as mean \pm S.E.M. of at least three replicates. ${ }^{*} P<0.05$, ${ }^{*} P<0.01$

different phenotypes in spermiogenic defects observed, further studies are required to understand their downstream effectors in the process of spermiogenesis.

Spermatogenesis - the differentiation of male germ cells is a specialized developmental process, which is precisely regulated at the transcriptional, posttranscriptional, and translational levels. ${ }^{52,53}$ Following meiosis, the beginning of spermiogenesis is characterized by a massive wave of transcription in round spermatids and subsequent expression of genes are required for morphological and biochemical reprogramming. ${ }^{54}$ To date, only a limited number of genes were identified as key regulators of spermiogenesis, including Crem, Rnf17, Tpap, Ddx25, Trf2, Rfx2, Piwil and Boule..$^{15-24}$ Accordingly, our results suggest a selective downregulation of these key regulators during spermiogenesis in cKO testis. However, the decreased gene expression levels stemming from $L k b 1 \mathrm{cKO}$ testis provided some but not sufficient support for the completion of spermiogenesis.

The detrimental effects of aberrant activation of mTORC1 in stem cell maintenance have been extensively reported. ${ }^{35,39,55}$ Moreover, the important roles of mTORC1 in SSC differentiation have emerged in recent years. ${ }^{56-59}$ As the major upstream 
kinase to phosphorylate AMPK, LKB1 is best known to inhibit mTORC1 activity through activation of AMPK. ${ }^{2}$ We inferred aberrant activation of mTORC1 results in accelerating SSC differentiation. However, our following experiments using in vivo rapamycin treatment failed to rescue the defects on SSC maintenance. Furthermore, to some extent, this treatment slightly accelerated germ cell depletion in Lkb1 cKO mice. Therefore, based upon these results, the effects on SSC differentiation stemming from $L k b 1$ deletion cannot be solely due to a downstream effect on the mTOR signaling pathway, and other mechanisms must be in place in the regulation of LKB1 on SSC maintenance and survival.

As an evolutionarily conserved regulator of cellular energy metabolism, the involvement of LKB1 in stem cell maintenance has been only reported in HSCs. ${ }^{41}$ Inactivation of $L k b 1$ in mice caused progressive depletion of HSCs and eventual pancytopenia. Although the deletion of $L k b 1$ was associated with predictable loss of p-AMPKa and an increase in $\mathrm{p}$-rpS6, it was shown that $L k b 1$ regulation of $\mathrm{HSC}$ maintenance occurred in an AMPK- and mTORC1independent manner. ${ }^{41,60,61}$ Concurrently, the $L k b 1$-deficient HSCs exhibited mitochondrial defects, aneuploidy and ATP depletion. ${ }^{41,60,61}$ In our study, survival and maintenance of SSCs was also in an mTORC1-independent manner. And, a significant decrease of mitochondrial activity was observed in Lkb1-deficient SPCs. A stem cell niche was essential for maintenance of stem cell populations. ${ }^{62}$ Although this niche may be essentially different between HSCs and SSCs, similar phenotypes suggest that a common mechanism exists in the regulation of $L k b 1$ in adult stem cell homeostasis. It would be very beneficial to define the common and specific effectors when comparing the role of LKB1 in these two stem cell types. Since $L k b 1_{L}$ is the major isoform expressed in SSCs, our results revealed its indispensable role on maintenance of the stem potential in SSCs.

In summary, by using $L k b 1 \mathrm{cKO}$ mice, we demonstrated the differential regulation mediated by $L k b 1$ isoforms in spermatogenesis. Although $L k b 1_{S}$ is the dominant isoform expressed in testis and plays crucial roles in spermiogenesis, the $L k b 1_{L}$ was also required, with both isoforms functioning independently or coordinately at different stages of spermatogenesis. Our data suggest an indispensible role of $L k b 1_{L}$ in SSC maintenance and the cooperative regulations of both $L k b 1$ isoforms in spermatid differentiation.

\footnotetext{
Materials and Methods

Mouse genetics, husbandry and treatment. Mice carrying floxed Lkb1 alleles (FVB; 129S6-Stk11tm1Rdp/Nci) were obtained from NCI Mouse repository. Vasa-Cre mice were purchased from Model Animal Research Center of Nanjing University (Nanjing, Jiangsu, China). ${ }^{63}$ The floxed Lkb1 mouse strain was backcrossed onto a C57BL/6 background for at least nine times. The two strains were kept on the same genetic background $(\mathrm{C} 57 \mathrm{BL} / 6)$ and were bred by standard husbandry techniques to obtain conditional knockout mice with deletion $L k b 1$ gene in germ cells only ( $L k b 1 \mathrm{cKO}$ mice). The primers to detect wt and flox Lkb1 alleles are R1: 5'-CTGTGCTGCCTAATCTGTCG-3', F2: 5'-TTCACCATCCCTTGTGACTG $-3^{\prime}$ and F4: $5^{\prime}$-ATCGGAATGTGATCCAGCTT- $3^{\prime}{ }^{60}$ The mice were housed in the animal facility at Nanjing Medical University and all animal protocols were approved by the Committee on the Ethics of Animal Experiments of Nanjing Medical University. Testes at different developmental stages (P8, P24, 5 W, 6 W, 13 W, 20 W and $40 \mathrm{~W}$ ) were collected to evaluate morphology and other analyses.
}

To test the effect of rapamycin on SSC maintenance and differentiation, mice at P7 from control and $L k b 1 \mathrm{CKO}$ mice were treated daily with rapamycin $(4 \mathrm{mg} / \mathrm{kg}, \mathrm{LC}$ Laboratories, Woburn, MA, USA) or vehicle for 7 days as described ${ }^{39}$ and then raised until 5 weeks of age for testes collection.

Germ cell isolation and SSC culture. Germ cell isolation and SSC culture were established according to previous study. ${ }^{28}$ Briefly, germ cells were isolated from P8 of control and cKO mice and Thy-1-positive cells were enriched by using magnetic activated cell sorting (Miltenyi Biotech, Bergisch Gladbach, Germany). Cells were plated at a density of 1.5 to $2 \times 10^{5}$ per well on 12-well plates with mitotically inactivated STO feeder layers (ATCC, Manassas, VA, USA). Medium was replaced every 2-3 days and were passaged at a ratio of $1: 2$ every $5-6$ days. Cell numbers were counted at each passage in order to plot the cell growth curve. Cultures were maintained at $37{ }^{\circ} \mathrm{C}$ in an incubator with humidified $5 \% \mathrm{CO}_{2}$ and $95 \%$ air atmosphere.

Sta-put velocity sedimentation. Spermatogenic cell fractionation was performed by sedimentation of cells prepared from adult mouse testes through a BSA gradient as previously described with a modification. ${ }^{64}$ At least 30 testes were pooled from male mice at 5 weeks of age and incubated with $1 \mathrm{mg} / \mathrm{ml}$ collagenase IV in DMEM (Life Technology, Waltham, MA, USA) for $15-20$ min at $37^{\circ} \mathrm{C}$ in water bath and gently shook into seminiferous tubules. The cords were then washed twice in DMEM by sedimentation at unit gravity and decanting the supernatant. Further digestion were then performed with $1 \mathrm{mg} / \mathrm{ml}$ DNase I in 0.25\% trypsin for 5-15 min at $37^{\circ} \mathrm{C}$. Pellet cells at $500 \mathrm{~g}$ for $5 \mathrm{~min}$ and re-suspend pellet with wash buffer $(10 \%$ FBS, $0.5 \%$ BSA, $200 \mu \mathrm{g} / \mathrm{ul}$ DNase I). Monodisperse cell suspension was made after filtering the cells with $40 \mu \mathrm{m}$ cell strainer. The dispersed cells were layered over a linear gradient $(2-4 \%)$ of BSA in DMEM, then allow to sediment at unit gravity for a total period of $2.5-3 \mathrm{~h}$. The cells were collected, identified and pooled into quasihomogeneous populations. The isolated cell types were characterized on the expression of marker genes by RT-PCR.

Sperm counts and sperm staining. Adult wild-type and Lkb1 $\mathrm{cKO}$ mice (13 weeks of age) were killed and one caudal epididymidis was dissected from each mouse to collect spermatoza. The extruded spermatoza were incubated in $37^{\circ} \mathrm{C}$ PBS for 15 min and the suspension was diluted $1: 100$ for sperm counting using a hemocytometer. After cell counting, $10 \mu$ l of the diluted suspension was collected to draw a sperm smear. Then the smears were stained with eosin for morphological examination.

Immunohistochemistry and mmunoflurescence. Mouse testes were fixed in Hartman's Fixative (Sigma, MO, USA; H0292) overnight before embedding in paraffin. After deparaffinization and rehydration, tissue sections were then incubated for $15 \mathrm{~min}$ in $3 \%$ (v/v) hydrogen peroxide in methanol to block endogenous peroxidase activity and antigen retrieval was pretreated by boiling the tissue sections in $0.01 \mathrm{M}$ citrate buffer for $15 \mathrm{~min}$. Immunohistochemical analysis were performed using a SP-link Detection Kit (Zhong Shan Jin Qiao, Beijing, China; SP9001 for anti-rabbit, SP9002 for anti-mouse) with primary antibodies overnight at $4{ }^{\circ} \mathrm{C}$. Sections were counterstained with hematoxylin following detection. Primary antibodies used were as follows: p-rpS6 (CST, Cell Signaling Technology, Beverly, MA, USA; catalog no. 4858; $1: 800$ ) (CST,), PCNA (CST; catalog no. 13110; 1: 16000), Lin28a (Abcam, Cambridge, MA, USA; catalog no. 46020; $1: 2000$ ) and Plzf (R\&D Systems, Minneapolis, MN, USA; catalog no. AF2944; 1:500). Immunofluorescence was performed with antibodies for VASA (Abcam; catalog no. 13840; 1 : 400), GATA4 (Santa Cruz, CA, USA; catalog no. 25310; $1: 100$ ), $\gamma$ H2AX (Abcam; catalog no. 26350; $1: 400$ ) and p-rpS6 (CST). After incubation overnight at $4{ }^{\circ} \mathrm{C}$, the primary antibodies were washed out and sections were incubated with relative secondary antibodies at $\mathrm{RT}$ for $1 \mathrm{~h}$. The secondary antibodies include Alexa Fluor 488 donkey anti-rabbit (Invitrogen, Grand Island, NY, USA; catalog no. A21206; 1:500), Alexa Fluor 594 donkey anti-mouse (Invitrogen; catalog no. A21203; 1:500), Alexa Fluor 488 goat anti-mouse secondary antibodies (Invitrogen; catalog no. A21202; 1:500). Then the nuclei were stained with $0.01 \mathrm{mg} / \mathrm{ml}$ Hoechst 33342 (Invitrogen; catalog no. H1339) for $20 \mathrm{~min}$ and sections were viewed under a laser scanning confocal microscope (LSM 510 META, Zeiss, Germany).

Acrosome staining. Testes at 6 weeks of age were collected in both control and CKO mice. Tissues were fixed in Hartman's Fixative overnight, then incubated in 5 and $30 \%$ sucrose, embedded in optimum cutting temperature compound (OCT, Tissue-Tek, Torrance, CA, USA) and cut into $8 \mu \mathrm{m}$ sections using a microtome- 
cryostat (Thermo Cryotome FSE). Frozen sections were washed in PBS three times and permeabilized in $0.1 \%$ Triton $\mathrm{X}-100$ for $10 \mathrm{~min}$. After washing in PBS, sections were incubated with Fluorescein isothiocyanate-conjugated peanut agglutinin (FITCPNA, Sigma; catalog no. L7381; $1: 500$ ) at a final concentration of $10 \mu \mathrm{g} / \mathrm{ml}$ for $1 \mathrm{~h}$ at RT. The nuclei were counterstained with Hoechst 33342 and viewed under a laser scanning confocal microscope (LSM 510 META, Zeiss, Germany).

TUNEL assay. Testes were collected from three different control and mutant mice and fixed overnight at RT in Hartman's Fixative (Sigma). TUNEL assays were performed on $5 \mu \mathrm{m}$ sections with the In Situ Cell Death Detection Kit (Roche Applied Science, Indianapolis, IL, USA; catalog no. 12156792910) according to the manufacturer's instructions.

Western blots. Testes from control and Lkb1 cKO mice were collected and proteins were extracted by RIPA lysis buffer (Beyotime Institute of Biotechnology, Shanghai, China; catalog no. P0013B) with protease inhibitor cocktails (Amresco, Solon, OH, USA; catalog no. M221). After electrophoresis and electronic transfer, the membranes were blocked in 5\% skimmed milk-TBST (TBS containing $0.1 \%$ Tween 20) for $30 \mathrm{~min}$ and then incubated overnight at $4{ }^{\circ} \mathrm{C}$ with specific antibodies. The following antibodies are used: LKB1 (CST; catalog no. 3047; 1 : 1000), p-S6K1 (phosphorylated at Thr389; CST; catalog no. 9234; 1: 1000), rpS6 (CST; catalog no. 2217; $1: 1000$ ), p-rpS6 (CST), $\beta$-tubulin (CST; catalog no. 2128; $1: 2000$ ), Lin28a (Abcam; catalog no. 46026; 1 : 2000), Plzf (R\&D; catalog no. AF2944; $1:$ 1000), Akt (CST; catalog no. 2920; $1: 2000$ ) and p-Akt (CST; catalog no. 4060; $1: 2000$ ). Horseradish peroxidase-conjugated goat anti-rabbit (Zhong Shan Jin Qiao; catalog no. ZB2301; 1:2000), goat anti-mouse (Zhong Shan Jin Qiao; catalog no. ZB2305; $1: 2000$ ), rabbit anti-goat IgGs (Zhong Shan Jin Qiao; catalog no. ZB2306; 1:2000) were then used to detect proteins through enhanced chemiluminescence (Amersham, Pittsburgh, PA, USA).

Transmission electron microscopy (TEM). Adult caudal epididymidis (13 weeks) or testes at 6 weeks of age were fixed with $2.5 \%$ glutaraldehyde in $0.2 \mathrm{M}$ cacodylate buffer overnight and cut into small pieces $\left(1 \mathrm{~mm}^{3}\right)$ after washing in $0.2 \mathrm{M}$ cacodylate buffer. Small blocks were dehydrated through a graded ethanol series and embedded in resin. Ultrathin sections were cut on an ultramicrotome and observed with a transmission electron microscope (Tecnai G2 Spirit Bio TWIN).

Quantitative RT-PCR analysis. RNA was extracted from testes or germ cells using TRIzol reagent (Invitrogen) according to the manufacturer's instructions. Reverse transcription was performed on 500 ngRNA using HiScript II qRT super mix (Vazyme, Nanjing, China). Quantitative real-time PCR was performed using Eva green master mix (Applied Biological Materials Inc, Vancouver, Canada) on an ABI StepOne ${ }^{\mathrm{TM}}$ RealTime PCR System (Applied Biosystems, Foster City, CA, USA). The relative expression of each gene was calculated by a 2- $\Delta C T$ method with the expression of $\beta$-actin as internal control. All the primers for RT-PCR were seen in Supplementary Table S1.

Measurement of mitochondrial membrane potential $(\Delta \Psi \mathrm{m})$. To measure the mitochondrial membrane potential, SPCs were incubated for $20 \mathrm{~min}$ at $37^{\circ} \mathrm{C}$ with $5 \% \mathrm{CO}_{2}$ in SSC culture medium supplemented with $2 \mu \mathrm{M} \mathrm{JC}-1$ probe (Beyotime Institute of Biotechnology, Beijing, China), in accordance with the manufacturer's protocol. After washing twice, SPCs were analyzed immediately by confocal microscopy (LSM 700, Zeiss, Germany). JC-1 is a cationic dye that produces two fluorescence emission peaks, indicated by a fluorescence emission shift from green (JC-1 monomers) to red (JC-1 aggregates). Consequently, mitochondrial depolarization was indicated by a decrease in the red/green fluorescence intensity ratio.

Statistical analysis. All data are presented as the mean \pm S.E.M. and the statistical significance of the difference between control and cKO mice were examined using Student's $t$-test with a paired two-tailed distribution. The data were considered significance when $P<0.05\left(^{*}\right)$ or $0.01\left(^{* *}\right)$. Values were calculated by using Prism 5.0 for Macintosh (GraphPad Software, Inc., La Jolla, CA, USA).

\section{Conflict of Interest}

The authors declare no conflict of interest.
Acknowledgements. We would like to thank Prof. Eugene Xu and Prof. Xin Wu (State Key Laboratory of Reproductive Medicine, Nanjing Medical University, Nanjing, China) for their advices on our experimental design and the critical reviews of this paper.

\section{Author contributions}

$\mathrm{JL}$ and HW designed the study. FK, MW, XH, QY, XW, XD, XP, YJ performed the experiments. FK, TW and JL analyzed the data. FK, JYand JL wrote the manuscript.

\section{Publisher's Note}

Springer Nature remains neutral with regard to jurisdictional claims in published maps and institutional affiliations.

1. Korsse SE, Peppelenbosch MP, van Veelen W. Targeting LKB1 signaling in cancer. Biochim Biophys Acta 2013; 1835: 194-210.

2. Shaw RJ, Bardeesy N, Manning BD, Lopez L, Kosmatka M, DePinho RA et al. The LKB1 tumor suppressor negatively regulates mTOR signaling. Cancer Cell 2004; 6: 91-99.

3. Sun G, Tarasov Al, McGinty JA, French PM, McDonald A, Leclerc I et al. LKB1 deletion with the RIP2.Cre transgene modifies pancreatic beta-cell morphology and enhances insulin secretion in vivo. Am J Physiol Endocrinol Metab 2010; 298: E1261-E1273.

4. Shorning BY, Zabkiewicz J, McCarthy A, Pearson HB, Winton DJ, Sansom OJ et al. Lkb1 deficiency alters goblet and paneth cell differentiation in the small intestine. PLoS One 2009; 4: e4264.

5. Gurumurthy S, Hezel AF, Sahin E, Berger JH, Bosenberg MW, Bardeesy N. LKB1 deficiency sensitizes mice to carcinogen-induced tumorigenesis. Cancer Res 2008; 68: 55-63.

6. Denison FC, Hiscock NJ, Carling D, Woods A. Characterization of an alternative splice variant of LKB1. J Biol Chem 2009; 284: 67-76

7. Towler MC, Fogarty S, Hawley SA, Pan DA, Martin DM, Morrice NA et al. A novel short splice variant of the tumour suppressor LKB1 is required for spermiogenesis. Biochem J 2008; 416: 1-14.

8. Denison FC, Smith LB, Muckett PJ, O'Hara L, Carling D, Woods A. LKB1 is an essentia regulator of spermatozoa release during spermiation in the mammalian testis. Plos One 2011; 6: e28306

9. Buaas FW, Kirsh AL, Sharma M, McLean DJ, Morris JL, Griswold MD et al. Plzf is required in adult male germ cells for stem cell self-renewal. Nat Genet 2004; 36: 647-652.

10. Heyting C, Dietrich AJ, Moens PB, Dettmers RJ, Offenberg HH, Redeker EJ et al. Synaptonemal complex proteins. Genome 1989; 31: 81-87.

11. Lin YW, Hsu TH, Yen PH. Localization of ubiquitin specific protease 26 at blood-testis barrier and near Sertoli cell-germ cell interface in mouse testes. Int J Androl 2011; 34: e368-e377.

12. Gallardo T, Shirley L, John GB, Castrillon DH. Generation of a germ cell-specific mouse transgenic Cre line, Vasa-Cre. Genesis 2007; 45: 413-417.

13. Russell LD, Ettlin RA, Hikim AP, Clegg ED. Histological and Histopathological Evaluation of the Testis. Cache River Press: Clearwater, FL, 1990.

14. Berruti G, Paiardi C. Acrosome biogenesis: revisiting old questions to yield new insights Spermatogenesis 2011; 1: 95-98.

15. Blendy JA, Kaestner KH, Weinbauer GF, Nieschlag E, Schutz G. Severe impairment of spermatogenesis in mice lacking the CREM gene. Nature 1996; 380: 162-165.

16. Pan J, Goodheart M, Chuma S, Nakatsuji N, Page DC, Wang PJ. RNF17, a component of the mammalian germ cell nuage, is essential for spermiogenesis. Development 2005; 132 4029-4039.

17. Kashiwabara S, Noguchi J, Zhuang T, Ohmura K, Honda A, Sugiura S et al. Regulation of spermatogenesis by testis-specific, cytoplasmic poly(A) polymerase TPAP. Science 2002; 298: 1999-2002.

18. Tsai-Morris $\mathrm{CH}$, Sheng Y, Lee E, Lei KJ, Dufau ML. Gonadotropin-regulated testicular RNA helicase (GRTH/Ddx25) is essential for spermatid development and completion of spermatogenesis. Proc Natl Acad Sci USA 2004; 101: 6373-6378.

19. Horvath GC, Kistler WS, Kistler MK. RFX2 is a potential transcriptional regulatory factor for histone $\mathrm{H} 1 \mathrm{t}$ and other genes expressed during the meiotic phase of spermatogenesis. Biol Reprod 2004; 71: 1551-1559.

20. Zhang D, Penttila TL, Morris PL, Teichmann M, Roeder RG. Spermiogenesis deficiency in mice lacking the Trf2 gene. Science 2001; 292: 1153-1155.

21. Nantel F, Monaco L, Foulkes NS, Masquilier D, LeMeur M, Henriksen $\mathrm{K}$ et al. Spermiogenesis deficiency and germ-cell apoptosis in CREM-mutant mice. Nature 1996; 380: $159-162$.

22. Martianov I, Fimia GM, Dierich A, Parvinen M, Sassone-Corsi P, Davidson I. Late arrest of spermiogenesis and germ cell apoptosis in mice lacking the TBP-like TLF/TRF2 gene. Mol Cell 2001; $7:$ 509-515.

23. Deng W, Lin H. miwi, a murine homolog of piwi, encodes a cytoplasmic protein essential for spermatogenesis. Dev Cell 2002; 2: 819-830.

24. VanGompel MJ, Xu EY. A novel requirement in mammalian spermatid differentiation for the DAZ-family protein Boule. Hum Mol Genet 2010; 19: 2360-2369.

25. Schlatt S, Weinbauer GF. Immunohistochemical localization of proliferating cell nuclear antigen as a tool to study cell proliferation in rodent and primate testes. Int $J$ Androl 1994; 17: 214-222. 
26. Ward IM, Chen J. Histone H2AX is phosphorylated in an ATR-dependent manner in response to replicational stress. J Biol Chem 2001; 276: 47759-47762.

27. Zheng $\mathrm{K}$, Wu X, Kaestner KH, Wang PJ. The pluripotency factor LIN28 marks undifferentiated spermatogonia in mouse. BMC Dev Biol 2009; 9: 38.

28. Kubota $\mathrm{H}$, Brinster RL. Culture of rodent spermatogonial stem cells, male germline stem cells of the postnatal animal. Methods Cell Biol 2008; 86: 59-84.

29. Kubota $\mathrm{H}$, Avarbock MR, Brinster RL. Culture conditions and single growth factors affect fate determination of mouse spermatogonial stem cells. Biol Reprod 2004; 71: 722-731.

30. Mitchell RT, Cowan G, Morris KD, Anderson RA, Fraser HM, McKenzie KJ et al. Germ cell differentiation in the marmoset (Callithrix jacchus) during fetal and neonatal life closely parallels that in the human. Hum Reprod 2008; 23: 2755-2765.

31. Chen C, Ouyang W, Grigura V, Zhou Q, Carnes K, Lim H et al. ERM is required for transcriptional control of the spermatogonial stem cell niche. Nature 2005; 436: 1030-1034.

32. Oatley JM, Avarbock MR, Telaranta Al, Fearon DT, Brinster RL. Identifying genes important for spermatogonial stem cell self-renewal and survival. Proc Natl Acad Sci USA 2006; 103: 9524-9529.

33. Hermann BP, Sukhwani M, Simorangkir DR, Chu T, Plant TM, Orwig KE. Molecular dissection of the male germ cell lineage identifies putative spermatogonial stem cells in rhesus macaques. Hum Reprod 2009; 24: 1704-1716.

34. Giuili G, Tomljenovic A, Labrecque N, Oulad-Abdelghani M, Rassoulzadegan M, Cuzin F. Murine spermatogonial stem cells: targeted transgene expression and purification in an active state. EMBO Rep 2002; 3: 753-759.

35. Gan B, DePinho RA. mTORC1 signaling governs hematopoietic stem cell quiescence. Cell Cycle 2009; 8: 1003-1006.

36. Jiang ZZ, Hu MW, Ma XS, Schatten H, Fan HY, Wang ZB et al. LKB1 acts as a critical gatekeeper of ovarian primordial follicle pool. Oncotarget 2016; 7: 5738-5753.

37. Han D, Li SJ, Zhu YT, Liu L, Li MX. LKB1/AMPK/mTOR signaling pathway in non-small-cell lung cancer. Asian Pac J Cancer Prev 2013; 14: 4033-4039.

38. Chen C, Liu Y, Liu R, Ikenoue T, Guan KL, Liu Y et al. TSC-mTOR maintains quiescence and function of hematopoietic stem cells by repressing mitochondrial biogenesis and reactive oxygen species. J Exp Med 2008; 205: 2397-2408.

39. Yilmaz OH, Valdez R, Theisen BK, Guo W, Ferguson DO, Wu H et al. Pten dependence distinguishes haematopoietic stem cells from leukaemia-initiating cells. Nature 2006; 441 : 475-482.

40. Chakraborty P, Buaas FW, Sharma M, Snyder E, de Rooij DG, Braun RE. LIN28A marks the spermatogonial progenitor population and regulates its cyclic expansion. Stem Cells 2014; 32: $860-873$.

41. Gurumurthy S, Xie SZ, Alagesan B, Kim J, Yusuf RZ, Saez B et al. The Lkb1 metabolic sensor maintains haematopoietic stem cell survival. Nature 2010; 468: 659-663.

42. Prathapan A, Vineetha VP, Raghu KG. Protective effect of Boerhaavia diffusa L. against mitochondrial dysfunction in angiotensin II induced hypertrophy in $\mathrm{H} 9 \mathrm{c2}$ cardiomyoblast cells. PLoS One 2014; 9: e96220.

43. Clermont Y, RO, Hermo. L. Cell Biology of Mammalian Spermatogenesis. Oxford University Press: New York, 1993.

44. Boehlke C, Kotsis F, Patel V, Braeg S, Voelker H, Bredt S et al. Primary cilia regulate mTORC1 activity and cell size through Lkb1. Nat Cell Biol 2010; 12: 1115-U1126.

45. Gloerich M, ten Klooster JP, Vliem MJ, Koorman T, Zwartkruis FJ, Clevers H et al. Rap2A links intestinal cell polarity to brush border formation. Nat Cell Biol 2012; 14: 793-801.

46. Rodriguez-Fraticelli AE, Auzan M, Alonso MA, Bornens M, Martin-Belmonte F. Cell confinement controls centrosome positioning and lumen initiation during epithelial morphogenesis. J Cell Biol 2012; 198: 1011-1023.

47. Ossipova O, Bardeesy N, DePinho RA, Green JB. LKB1 (XEEK1) regulates Wnt signalling in vertebrate development. Nat Cell Biol 2003; 5: 889-894.

48. Fu A, Ng AC, Depatie C, Wijesekara N, He Y, Wang GS et al. Loss of Lkb1 in adult beta cells increases beta cell mass and enhances glucose tolerance in mice. Cell Metab 2009; 10: 285-295.
49. Granot Z, Swisa A, Magenheim J, Stolovich-Rain M, Fujimoto W, Manduchi E et al. LKB1 regulates pancreatic beta cell size, polarity, and function. Cell Metab 2009; 10: 296-308.

50. Nakano A, Kato H, Watanabe T, Min KD, Yamazaki S, Asano $Y$ et al. AMPK controls the speed of microtubule polymerization and directional cell migration through CLIP-170 phosphorylation. Nat Cell Biol 2010; 12: 583-590.

51. Akhmanova A, Mausset-Bonnefont AL, van Cappellen W, Keijzer N, Hoogenraad CC, Stepanova T et al. The microtubule plus-end-tracking protein CLIP-170 associates with the spermatid manchette and is essential for spermatogenesis. Genes Dev 2005; 19: 2501-2515.

52. Hecht NB. Molecular mechanisms of male germ cell differentiation. Bioessays 1998; 20: 555-561.

53. Steger K. Transcriptional and translational regulation of gene expression in haploid spermatids. Anat Embryol (Berl) 1999; 199: 471-487.

54. Eddy EM. Male germ cell gene expression. Recent Prog Horm Res 2002; 57: 103-128.

55. Castilho RM, Squarize CH, Chodosh LA, Williams BO, Gutkind JS. mTOR mediates Wnt-induced epidermal stem cell exhaustion and aging. Cell Stem Cell 2009; 5: 279-289.

56. Hobbs RM, Seandel M, Falciatori I, Rafii S, Pandolfi PP. Plzf regulates germline progenitor self-renewal by opposing mTORC1. Cell 2010; 142: 468-479.

57. LaFever L, Feoktistov A, Hsu HJ, Drummond-Barbosa D. Specific roles of Target of rapamycin in the control of stem cells and their progeny in the Drosophila ovary. Development 2010; 137: 2117-2126.

58. Sun P, Quan Z, Zhang B, Wu T, Xi R. TSC1/2 tumour suppressor complex maintains Drosophila germline stem cells by preventing differentiation. Development 2010; 137: 2461-2469.

59. Sahin P, Sahin Z, Gungor-Ordueri NE, Donmez BO, Celik-Ozenci C. Inhibition of mammalian target of rapamycin signaling pathway decreases retinoic acid stimulated gene 8 expression in adult mouse testis. Fertil Steril 2014; 102: 1482-1490 e1483.

60. Nakada D, Saunders TL, Morrison SJ. Lkb1 regulates cell cycle and energy metabolism in haematopoietic stem cells. Nature 2010; 468: 653-658.

61. Gan B, Hu J, Jiang S, Liu Y, Sahin E, Zhuang $L$ et al. Lkb1 regulates quiescence and metabolic homeostasis of haematopoietic stem cells. Nature 2010; 468: 701-704.

62. Kostereva N, Hofmann MC. Regulation of the spermatogonial stem cell niche. Reprod Domest Anim 2008; 43(Suppl 2): 386-392.

63. Bardeesy N, Sinha M, Hezel AF, Signoretti S, Hathaway NA, Sharpless NE et al. Loss of the Lkb1 tumour suppressor provokes intestinal polyposis but resistance to transformation. Nature 2002; 419: 162-167.

64. Bryant JM, Meyer-Ficca ML, Dang VM, Berger SL, Meyer RG. Separation of spermatogenic cell types using STA-PUT velocity sedimentation. J Vis Exp 2013; 80: e50648.

(c) (i) Cell Death and Disease is an open-access journal published by Nature Publishing Group. This work is licensed under a Creative Commons Attribution 4.0 International License. The images or other third party material in this article are included in the article's Creative Commons license, unless indicated otherwise in the credit line; if the material is not included under the Creative Commons license, users will need to obtain permission from the license holder to reproduce the material. To view a copy of this license, visit http://creativecommons.org/licenses/by/4.0/

(C) The Author(s) 2017

Supplementary Information accompanies this paper on Cell Death and Disease website (http://www.nature.com/cddis) 